\title{
Thermo-mechanical behaviour of clay-structure interface
}

\author{
Soheib Maghsoodi ${ }^{1,2, *}$, Olivier Cuisinier ${ }^{1}$, and Farimah Masrouri ${ }^{1}$ \\ ${ }^{1}$ Université de Lorraine, CNRS, LEMTA, Nancy, France \\ ${ }^{2}$ École supérieure d'ingénieurs des travaux de la construction de Metz, Metz, France
}

\begin{abstract}
The mechanical behaviour of the soil-structure interface plays a major role in the shear characteristics and bearing capacity of foundations. In thermo-active structures, due to non-isothermal conditions, the interface behaviour becomes more complex. The objective of this study is to investigate the effects of temperature variations on the mechanical behaviour of soils and soil-structure interface. Constant normal load (CNL) and constant normal stiffness (CNS) tests were performed on soil and soil-structure interface in a direct shear device at temperatures of 5,22 and $60{ }^{\circ} \mathrm{C}$. Kaolin clay was used as proxy for clayey soils. The results showed that, in clay samples the temperature increase, increased the cohesion and consequently the shear strength, due to thermal contraction during heating. The temperature rise had less impact on the shear strength in the case of the clay-structure interface than in the clay samples. The adhesion of the clay-structure interface, is less than the cohesion of the clay samples.
\end{abstract}

\section{Introduction}

The soil-structure interactions at the interface are of primary importance in foundation designs. In energy geostructures the mechanical loads applied to the structure on one hand, and the effect of heat exchange between structure and surrounding soil on the other hand, modify the behaviour of the soil-structure interface. These thermal variations and mechanical loads affect the bearing capacity and frictional resistance of these thermo-active structures. Therefore, the effects of temperature on the soil-structure interface mechanical parameters should be investigated.

An important concept to aid in understanding the interface behaviour is the constant normal stiffness (CNS) conditions. Depending on the volumetric response of the soil at the interface during shearing, the surrounding soil stiffness constrains the volumetric response of the interface and acts as a virtual spring with a given stiffness [1] (Eq. 1).

$$
\Delta \sigma=-K . \Delta U
$$

Where $\Delta \sigma(\mathrm{kPa})$ is the normal stress difference, $K$ $(\mathrm{kPa} / \mathrm{mm})$ is the stiffness of the adjacent soil (stiffness of the spring) and $\Delta U(\mathrm{~mm})$ is the normal displacement difference of the interface.

The tendency of the interface to dilate is counteracted by the elastic reaction of the adjacent soil [2]. In the literature constant normal load (CNL) and constant normal stiffness (CNS) tests on sand-steel interface is performed [3] and the results showed that the effect of the normal stiffness $(K)$ on the mobilized shear resistance of the interfaces in CNS tests depends on the volumetric response exhibited by the interfaces in the CNL tests. They showed that in dilative regimes, the increase in the current normal stress

*e-mail: soheib.maghsoodi@univ-lorraine.fr $\left(\sigma_{n}\right)$ when sheared in the CNS tests causes an increase in the current shear stress $(\tau)$. On the other hand, in the contractive regimes (smooth interface or loose soil), a decrease in the normal and shear stresses is observed. They showed that the variation of the mobilized shear resistance during the CNS tests is a consequence of the current normal stress evolution and the mobilized sand-structure friction angle remains unchanged.

Another important factor that influences the soilstructure interactions is the structure surface roughness ([3], [4]). Normalized roughness $\left(R_{n}\right)$, as reported by [5], was defined by measuring $R_{\text {max }}$ (vertical distance between the highest peak and lowest valley) along a profile length $L$ equal to the mean grain size $D_{50}$ and then normalized by $D_{50}$ :

$$
R_{n}=\frac{R_{\max }\left(L=D_{50}\right)}{D_{50}}
$$

Previous investigations [6] indicate a range for the smooth and rough surfaces. The critical roughness $\left(R_{\text {crit }}=\right.$ $0.1-0.13)$ was chosen as a range that $\left(R_{n}>R_{\text {crit }}\right)$ is a rough surface and $\left(R_{n}<R_{c r i t}\right)$ is considered as a smooth one.

Different studies have been performed on the effects of temperature on the mechanical parameters of soils ([7], [8], [9]) and these studies indicated that the thermomechanical behaviour of soils is highly dependent on the stress and thermal history of the material. However, only a few studies have been performed on the soil-structure interactions under non-isothermal conditions ([10], [11]). Interface direct shear tests on quartz sand and illite clay at different temperatures $\left(22,50\right.$ and $\left.60{ }^{\circ} \mathrm{C}\right)$ is performed [10]. These tests showed that the sand-concrete interface behaviour was not directly affected by temperature changes, but the clay-concrete interface showed higher 
shear strength at higher temperatures. The residual interface friction angle of the clay-concrete decreased slightly at high temperatures, but the adhesion (cohesion between soil and structure) increased with increasing temperature. The authors suggested that this result is related to the thermal consolidation of the clay, which results in an increase of the contact surface between the clay and concrete. In the other study ([11]), the soil-structure interface direct shear tests on Fontainebleau sand and kaolin clay samples at 5, 20 and $40{ }^{\circ} \mathrm{C}$ is conducted. The results showed that, the shear strength of the clay samples was higher than that of the clay-concrete interface, and the effects of temperature (in the range of $5-40{ }^{\circ} \mathrm{C}$ ) on the shear strength and friction angle were negligible in the sand, clay and clay-concrete interface. They pre-consolidated all the samples to 100 $\mathrm{kPa}$ of vertical stress and heated to $40{ }^{\circ} \mathrm{C}$ prior to the application of the initial conditions. Therefore, they found that the effect of temperature on the clay-concrete interface, which was mainly related to thermal consolidation, was negligible.

According to the literature, the effects of temperature on the friction angle and adhesion of the soil-structure interface, are poorly understood under both CNL and CNS conditions. In this study, a temperature-controlled direct shear device was used to perform interface tests on kaolin clay on a rough surface under CNL and CNS conditions, to better understand the following:

- The effects of temperature on the shear strength (friction angle, cohesion and adhesion) of soil and soil-structure interface under CNL and CNS conditions.

- The effect of surrounding soil stiffness on the soilstructure interface mechanical behaviour at different temperatures.

- The soil and soil-structure interface volumetric changes during heating (from 22 to $60^{\circ} \mathrm{C}$ ) and cooling (from 22 to $5^{\circ} \mathrm{C}$ ) under constant isotropic stress.

\section{Material properties, device and experimental programme}

\subsection{Material properties}

Kaolin clay used in this study has a liquid limit $L L=57 \%$ and Plastic limit $P L=33 \%$. To perform soil-structure interface direct shear tests, a stainless steel plate $(80 \times 60$ x $10 \mathrm{~mm}$ ) with the desired roughness was designed and used as the structure. This steel plate is used to, avoid abrasion of the surface due to test repetition. The roughness of the steel plate was measured with a laser profilometer. Four profiles with lengths of $32 \mathrm{~mm}$ parallel to the shear direction were measured. The stainless steel plate is considered a very rough surface for kaolin clay.

\subsection{Temperature-controlled direct shear device}

The shear box $(60 \times 60 \times 35 \mathrm{~mm})$ was placed inside a container filled with water to reach saturated conditions. The heating system consisted of a heater that controlled the fluid temperature circulating in the lower part of the container. Therefore, the water temperature in the container reached the same temperature as the circulating fluid. Three thermocouples, one in the lower half of the shear box, another on the upper half of the shear box and the last in the container, controlled the applied temperature. In this direct shear device, normal stress $\sigma_{n}(\mathrm{kPa})$, shear displacement $W(\mathrm{~mm})$, circulating fluid temperature $T\left({ }^{\circ} \mathrm{C}\right)$ and stiffness value $K(\mathrm{kPa} / \mathrm{mm})$ were applied, and vertical displacement $U(\mathrm{~mm})$, shear stress $\tau(\mathrm{kPa})$, and sample temperature $T\left({ }^{\circ} \mathrm{C}\right)$ were measured.

\subsection{Experimental programme}

The experimental programme consisted of soil and soilstructure direct shear tests at different temperatures (Fig. 1). Soil tests were performed as reference cases for comparison with soil-structure tests to better clarify the role of interface.

To perform the clay and clay-structure shear tests, kaolin clay was prepared with a water content of $63 \%$, which was slightly higher than its liquid limit $(L L=57 \%)$ and the sample was left for 24 hours for homogenization. Subsequently, the clay was poured into the shear box and special attention was paid to avoid any air trap. To perform the CNL tests at $22^{\circ} \mathrm{C}$, the normal stress was applied slowly and incrementally during the consolidation phase, and each load increment lasted 2 hours, to ensure full consolidation at each step ([12]). Two values of initial effective normal stresses $\left(\sigma_{n 0}^{\prime}=100,300 \mathrm{kPa}\right)$ were chosen for the clay programme. Based on the consolidation tests performed on this kaolin clay, the target void ratios after consolidation for $\sigma_{n}^{\prime}=100$ and $300 \mathrm{kPa}$ were $e=1$ and 0.85 , respectively. After the consolidation phase for the $\mathrm{CNL}$ tests at $22{ }^{\circ} \mathrm{C}$, a displacement rate of $0.006 \mathrm{~mm} / \mathrm{min}$ that was calculated from the settlement curve and $t_{50}$ (time required for the specimen to achieve 50 percent consolidation under the maximum normal stress) of the kaolin, was applied [13]. This slow rate ensured drained conditions inside the shear box during shearing. The initial heating or cooling phase started at ambient temperature $\left(22^{\circ} \mathrm{C}\right)$. After the consolidation phase, heating or cooling was applied to the samples at a rate of $5{ }^{\circ} \mathrm{C} / \mathrm{hr}$. This slow rate avoids a pore pressure increase during the heating phase and was verified by [9] and [10]. During the heating or cooling phase in the shear box, thermal vertical deformation of the soil and the soil-structure interface was measured. After these heating or cooling phases, the samples were sheared. For the CNL tests of the clay and clay-structure interface, paths 1-2 and 5-2' were applied, as seen in Fig. 1, but for the CNS clay-structure interface tests, paths $1-4$ and 5-4' were observed due to the normally consolidated state of the kaolin samples.

\section{Experimental results for clay}

\subsection{Clay}

After consolidation and reaching the desired void ratio, a heating or cooling phase at a rate of $5^{\circ} \mathrm{C} / \mathrm{hr}$, was applied to the clay samples. This heating and cooling caused a 


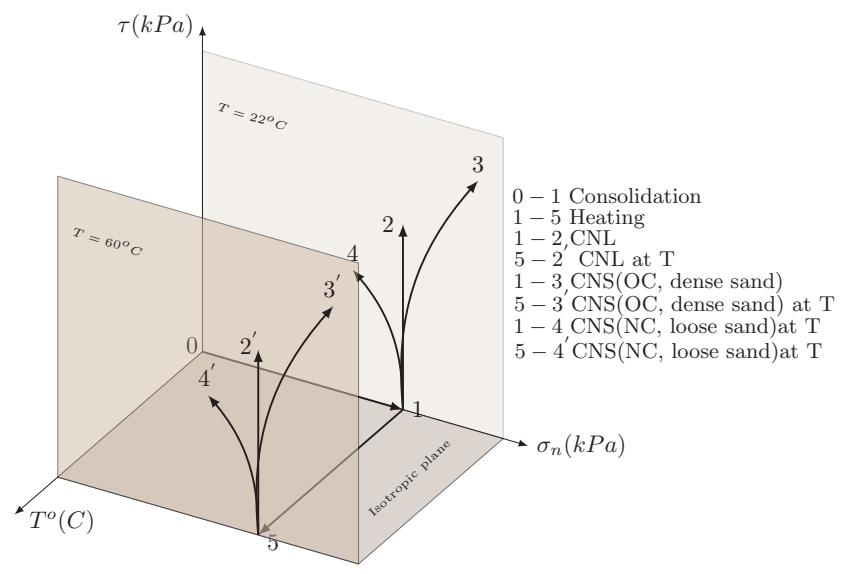

Fig. 1. Thermo-mechanical path performed in this study.

thermal vertical deformation under constant effective normal stresses of 100 and $300 \mathrm{kPa}$. The thermal vertical strain was higher for heating cases $(0.6-0.64 \%)$ than cooling cases $(0.18-0.2 \%)$.

After heating or cooling, normally consolidated kaolin clay samples were sheared at two different effective normal stresses $\left(\sigma_{n 0}^{\prime}=100,300 \mathrm{kPa}\right)$ at 5,22 and $60{ }^{\circ} \mathrm{C}$ (Fig. 2). In Fig. 2a, the shear stress-shear displacement curves for $100 \mathrm{kPa}$ and $300 \mathrm{kPa}$ at 5, 22 and $60{ }^{\circ} \mathrm{C}$ are presented. As observed for both effective normal stresses, the shear stress increased with increasing temperature, until the peak values, then it decreased towards the critical state. The residual shear stresses at 5,22 and $60{ }^{\circ} C$ for $\sigma_{n 0}^{\prime}=100$ $\mathrm{kPa}$ became convergent after a shear displacement of 5 $\mathrm{mm}$. For $\sigma_{n 0}^{\prime}=300 \mathrm{kPa}$ at 5 and $22{ }^{\circ} \mathrm{C}$ the shear stresses are similar up to a shear displacement of $\mathrm{W}=3.5 \mathrm{~mm}$. In the volumetric response, the samples that were exposed to higher temperatures showed less contraction during shear (Fig. 2b). For example in $100 \mathrm{kPa}$ of effective normal stress, the test at $5{ }^{\circ} \mathrm{C}$ showed a contraction approximately $0.89 \mathrm{~mm}$, but for the tests at 22 and $60{ }^{\circ} \mathrm{C}$, this amount decreased to approximately $0.68 \mathrm{~mm}$ and $0.38 \mathrm{~mm}$ respectively. For $300 \mathrm{kPa}$, the same trend was observed for the volumetric response.

The internal friction angle of the clay soil obtained at different temperatures, shows a slight increase with temperature increase $\left(14.4^{\circ}\right.$ to $\left.15.3^{\circ}\right)$. The main difference was the cohesion increase from 11 to $17 \mathrm{kPa}$ and then to $23 \mathrm{kPa}$ for tests at 5,22 and $60^{\circ} \mathrm{C}$, which could be due to thermal hardening during the heating phase (Fig. 2c).

\subsection{Clay-structure}

\subsubsection{CNL}

For clay-structure tests, the thermal vertical strain caused by the temperature increase from 22 to $60{ }^{\circ} \mathrm{C}$ was approximately $0.85 \%$, and for a temperature decrease from 22 to $5{ }^{\circ} \mathrm{C}$ in the cooling case, the thermal vertical strain was approximately $0.2 \%$ for the clay-structure interface tests.

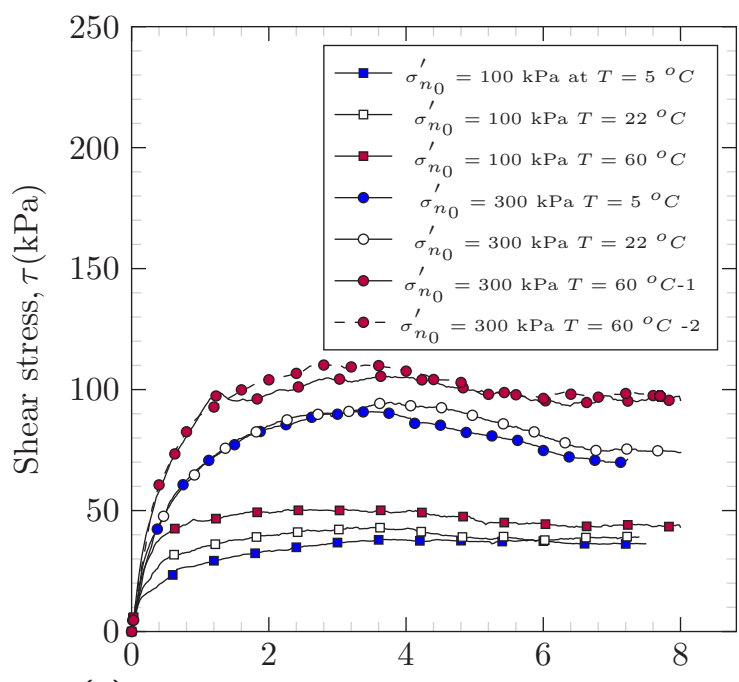

(a) Shear displacement, $W(\mathrm{~mm})$

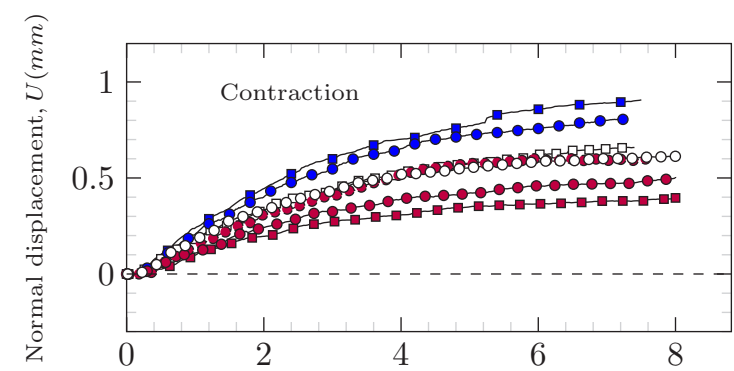

(b) Shear displacement, $W(\mathrm{~mm})$

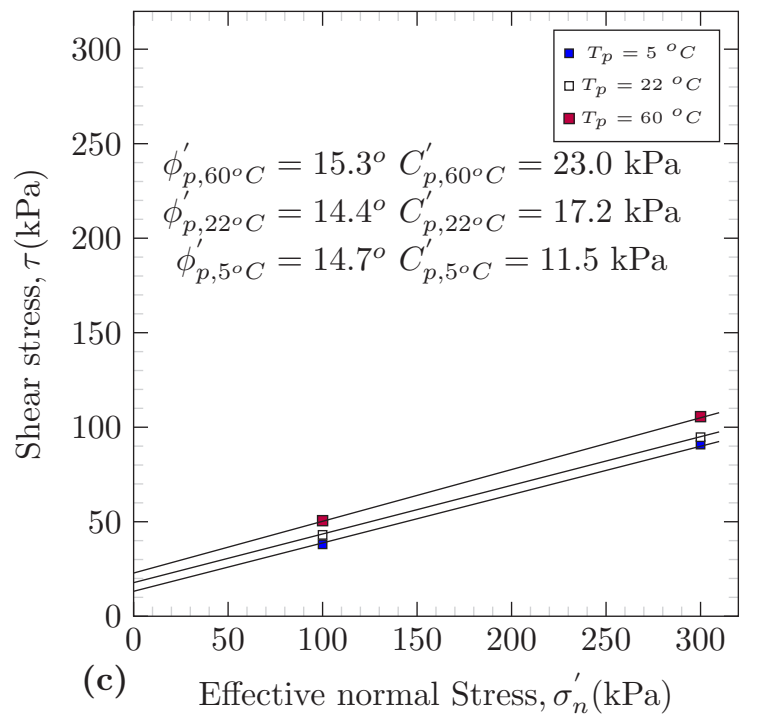

Fig. 2. Clay CNL results at different temperatures.

In Fig. 3 the results of the clay-structure interface CNL tests are presented. Fig. 3a shows the shear stress versus shear displacement for $\sigma_{n 0}^{\prime}=100 \mathrm{kPa}$. The peak shear strength curve was slightly higher at $60{ }^{\circ} \mathrm{C}$ than at 5 and $22{ }^{\circ} C(\Delta \tau=8 \mathrm{kPa})$, but at the critical state, all curves at different temperatures were superimposed. For $\sigma_{n 0}^{\prime}=300$ $\mathrm{kPa}$, the $\Delta \tau=10 \mathrm{kPa}$ of difference at the peak was evident for $60{ }^{\circ} \mathrm{C}$ compared to 5 and $22{ }^{\circ} \mathrm{C}$. In the critical state, the same behaviour as $\sigma_{n 0}^{\prime}=100 \mathrm{kPa}$ was observed. 

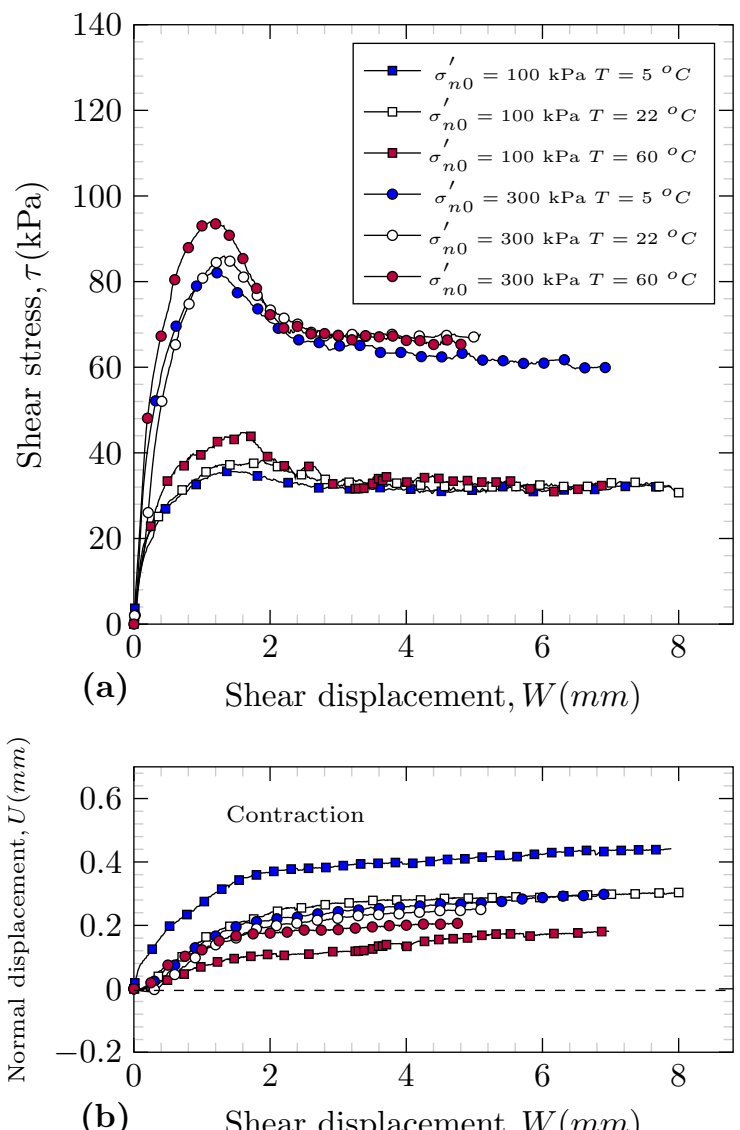

Fig. 3. Clay-structure CNL results at different temperatures.

In Fig. $3 b$ the volumetric behaviours of the claystructure interface are presented for $\sigma_{n 0}^{\prime}=100$ and $300 \mathrm{kPa}$. For $\sigma_{n 0}^{\prime}=100 \mathrm{kPa}$, the amount of contraction was $0.4 \mathrm{~mm}$ for the test at $5{ }^{\circ} \mathrm{C}$, while it was $0.28 \mathrm{~mm}$ and $0.12 \mathrm{~mm}$ for the tests at 22 and $60{ }^{\circ} \mathrm{C}$, respectively. For $\sigma_{n 0}^{\prime}=300 \mathrm{kPa}$, the same behaviour was observed, and the contraction at 5 ${ }^{\circ} \mathrm{C}$ was higher than those obtained at 22 and $60{ }^{\circ} \mathrm{C}$.

Fig. 4 shows the Mohr-Coulomb plane for the claystructure interface CNL tests at different temperatures. The peak friction angle for all studied temperatures was $14^{\circ}$. The main difference between the Mohr-Coulomb envelopes for different temperatures was the adhesion. The increase in temperature, increased the peak adhesion (cohesion between soil and structure) from $12.5 \mathrm{kPa}$ to $18 \mathrm{kPa}$ while the residual adhesion remained constant (16.5 kPa).

\subsubsection{CNS}

To investigate the shear characteristics of the claystructure interface, constant normal stiffness (CNS) conditions were applied. The results for $K=1000 \mathrm{kPa} / \mathrm{mm}$ that is intermediate value between $K=500(\mathrm{CNL})$ and $5000 \mathrm{kPa} / \mathrm{mm}(\mathrm{CV})$ are presented.

The shear stress versus shear displacement for two initial normal stresses $\left(\sigma_{n 0}^{\prime}=100\right.$ and $\left.300 \mathrm{kPa}\right)$ at different temperatures $\left(22\right.$ and $60^{\circ} \mathrm{C}$ ) are presented in Fig. 5a. At

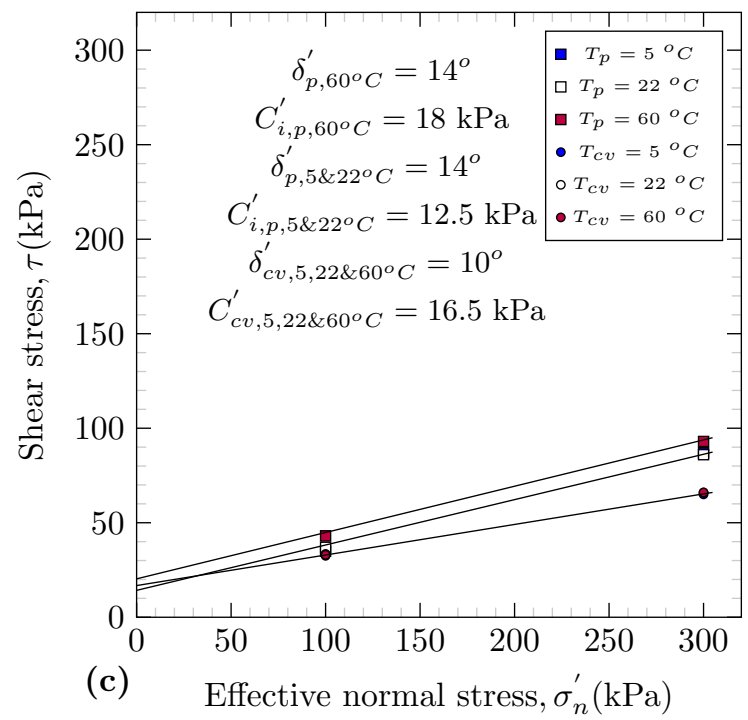

Fig. 4. Mohr-Coulomb plane of clay-structure tests at different temperatures.

$\sigma_{n 0}^{\prime}=100 \mathrm{kPa}$, the shear stress increased with increasing shear displacement until reaching a value of $1 \mathrm{~mm}(\tau=33$ $\mathrm{kPa}$ ) then, with a slight decrease, the shear stress continued towards the critical state $(\tau=28 \mathrm{kPa})$. The curves for both 22 and $60{ }^{\circ} \mathrm{C}$ followed the same trend. For tests at $\sigma_{n 0}^{\prime}=300 \mathrm{kPa}$ the shear stress showed a very clear peak and then decreased towards a constant value. As mentioned for $100 \mathrm{kPa}$, under $\sigma_{n 0}^{\prime}=300 \mathrm{kPa}$, the shear stresses at 22 and $60{ }^{\circ} \mathrm{C}$ are similar.

For both initial normal stresses, kaolin contracted until the end of the shear (Fig. 5b). For the test at $\sigma_{n 0}^{\prime}=100 \mathrm{kPa}$ and $22{ }^{\circ} \mathrm{C}$, the amount of normal displacement in the critical state was around $0.035 \mathrm{~mm}$. This value was approximately $0.02 \mathrm{~mm}$ for tests at $60{ }^{\circ} \mathrm{C}$, and the heated samples showed less contraction. For the test at $\sigma_{n 0}^{\prime}=300 \mathrm{kPa}$ at 22 and $60{ }^{\circ} \mathrm{C}$, the normal displacement in the critical state was 0.9 and $0.6 \mathrm{~mm}$, respectively.

In Fig. 5c the variation of normal stress during CNS tests of clay-structure interface is presented. For both $\sigma_{n 0}^{\prime}=100$ and $300 \mathrm{kPa}$ the normal stresses decreased during shearing process. For samples exposed to higher temperatures the amount of reduction was less than samples at 22 ${ }^{\circ} \mathrm{C}$. For tests at $\sigma_{n 0}^{\prime}=100 \mathrm{kPa}$ at 22 and $60{ }^{\circ} \mathrm{C}$ the normal stress reduction was about 42 and $30 \mathrm{kPa}$ respectively.

In Fig. 5d, the normal stress vs. shear stress planes for the clay-structure interface $\mathrm{CNS}$ and $\mathrm{CNL}$ tests are presented. For $\sigma_{n 0}^{\prime}=100$ and $300 \mathrm{kPa}$ in the CNS tests, the shear stress increased with decreasing normal stress, and the shear reached a peak value and then decreased. The heated samples showed less decrease in the normal stress compare to unheated samples. For example, for $\sigma_{n 0}^{\prime}=300 \mathrm{kPa}$, the peak shear strength for heated samples was slightly higher than $22{ }^{\circ} \mathrm{C}$, and the normal stress decrease in the heated sample was also less than that at 22 ${ }^{o} \mathrm{C}$. The peak friction angle and adhesion of the CNS tests were $14^{\circ}$ and $13 \mathrm{kPa}$ respectively. 

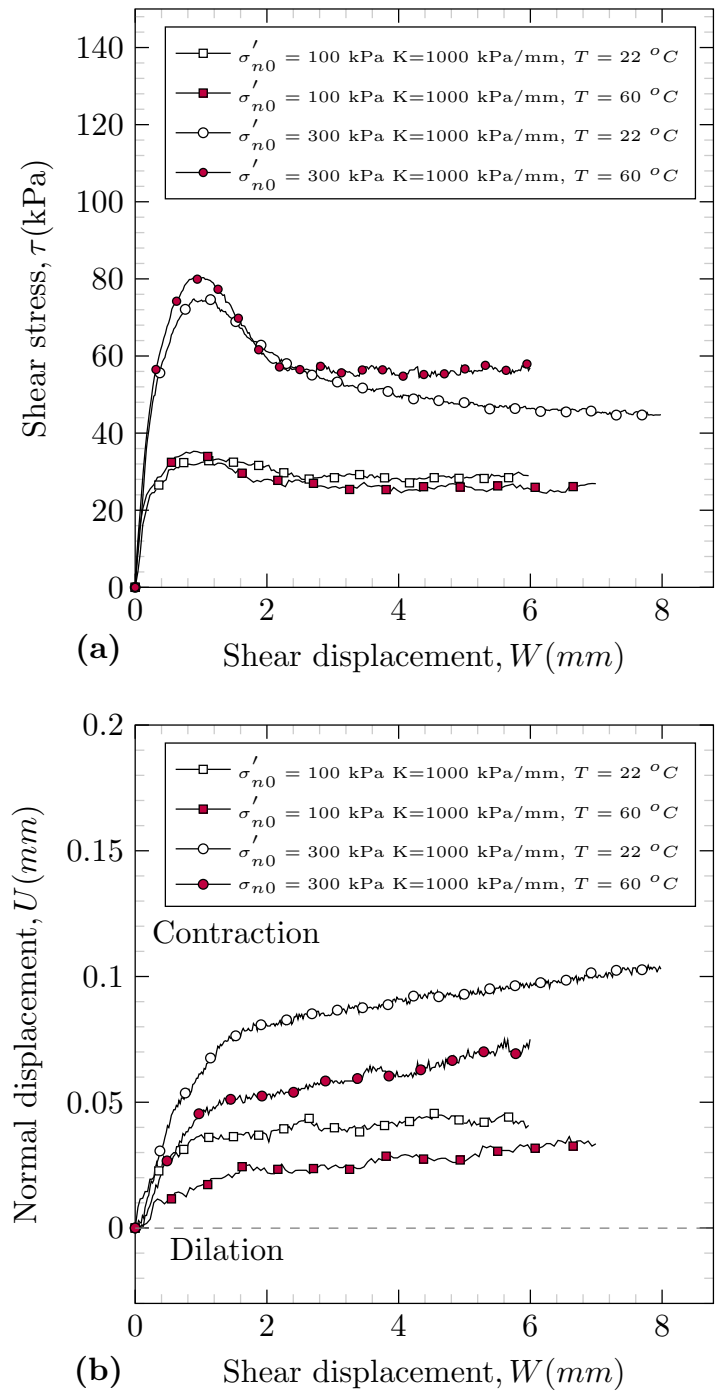

Fig. 5. Clay-structure CNS results at different temperatures.

\section{Discussion}

\subsection{Effect of temperature on clay}

The peak and residual shear strength in the clay-structure tests, were always less than those obtained during clay tests. This showed that the shearing occurred at the interface zone. Moreover, the peak shear stresses of the claystructure tests are close to the residual shear stress values of clay tests at all tested temperatures. This may be due to the sliding, or partially sliding, shear mode along the interface. Indeed, [16] showed that, in clays with high clay content in which residual soil shear is in the sliding mode, peak interface shear strength normally is close to the soil residual strength and is independent of roughness. Therefore, in the clay-structure interface tests performed in this study, the sliding or partially sliding shear mode at interface occurred for all tested temperatures.

The peak cohesion of clay samples increases from 17 to $23 \mathrm{kPa}$ while the peak adhesion of clay-structure increases from 12 to $18 \mathrm{kPa}$ with temperature increase from

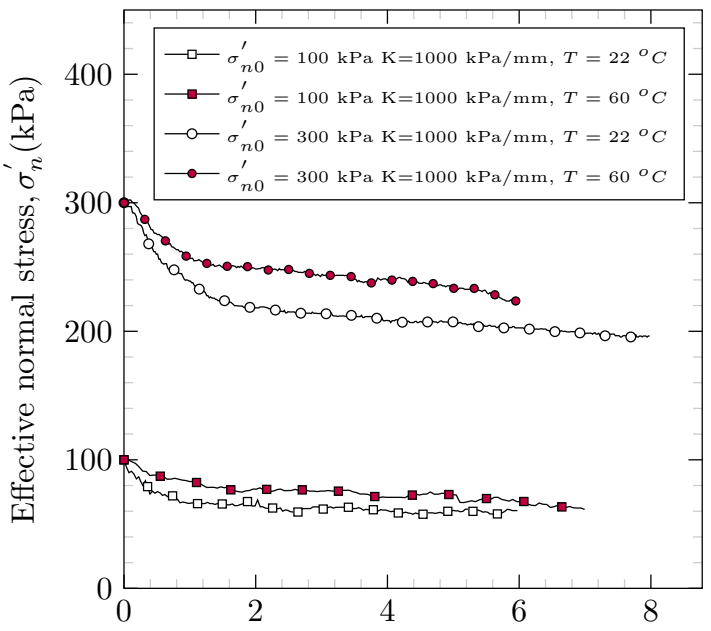

(c) Shear displacement, $W(\mathrm{~mm})$

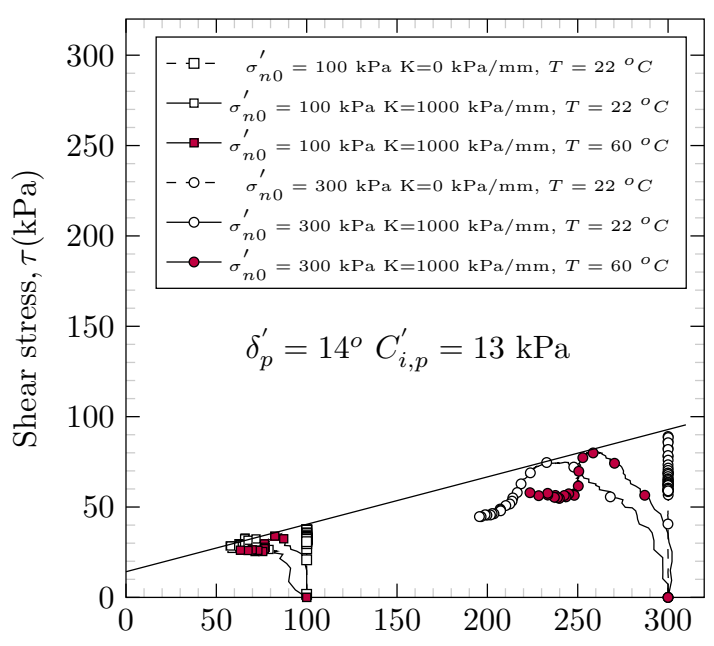

(d) Effective normal stress, $\sigma_{n}^{\prime}(\mathrm{kPa})$
22 to $60{ }^{\circ} \mathrm{C}$ while the residual adhesion remained stable. Therefore, it can be concluded that cohesion is more affected by temperature modification. This reflects the interaction between the structure and the clay. For kaolin clay, heating the interface tend to slightly increase the shear strength of the interface. Therefore, in terms of structural safety of energy geostructures, temperature increase in normally consolidated kaolin clay can be considered as a positive aspect.

In isothermal conditions, [17] have performed direct shear tests on different soils and different structural materials like steel, concrete and wood. He found that the friction angle and adhesion of a smooth steel interface is less than a smooth concrete interface. Therefore, it can be concluded that the nature of the structural material plays a major role in the interface behaviour and further works should be carried out to investigate the interface behaviour on different construction materials. 


\section{Conclusions}

Constant normal load (CNL) and constant normal stiffness (CNS) interface tests were conducted on clay and claystructure samples at different temperatures $(5,22$ and 60 $\left.{ }^{o} \mathrm{C}\right)$.

In kaolin clay, temperature does not affect the friction angle and the main effect is the increase of the cohesion or adhesion. For clay tests, due to thermal contraction of kaolin during heating, the soil becomes denser and shows a higher shear strength. It was found that temperature increases the cohesion of clay samples. In claystructure contact, due to difference in the nature of materials (clay vs. metal) the adhesion is not as much as clay case, therefore the shear strength increase with temperature increase, is not as much as clay case. In CNS tests on clay-structure interface, the soil exposed to higher temperatures, showed less contraction during shearing, and consequently less normal stress decrease due to the denser state of the heated clay-structure samples prior to shearing. Therefore, in the interface the soil becomes denser with heating and the shear strength increases slightly.

Further work will be carried out to investigate the effects of thermo-mechanical cycling on the mechanical behaviour of soil-structure interface.

\section{References}

[1] E. Wernick, Symposium on Soil Reinforcing and Stabilising Techniques in Engineering Practice 42, 201-219 (1978)

[2] V. Fioravante, V.N. Ghionna, S. Pedroni, D. Porcino, Rivista Italiana di geotecnica 33, 7 (1999)

[3] D. Porcino, V. Fioravante, V.N. Ghionna, S. Pedroni, Geotechnical Testing Journal 26, 289 (2003)

[4] L. Hu, J.L. Pu, Computers and Geotechnics 30, 165 (2003)

[5] M. Uesugi, H. Kishida, Soils and foundations 26, 139 (1986)

[6] M. Uesugi, H. Kishida, Y. Tsubakihara, Soils and foundations 29, 127 (1989)

[7] T. Hueckel, G. Baldi, Journal of geotechnical engineering 116, 1778 (1990)

[8] P. Delage, N. Sultan, Y.J. Cui, Canadian Geotechnical Journal 37, 343 (2000)

[9] C. Cekerevac, L. Laloui, International journal for numerical and analytical methods in geomechanics $\mathbf{2 8}$, 209 (2004)

[10] A. Di Donna, A. Ferrari, L. Laloui, Canadian Geotechnical Journal 53, 659 (2015)

[11] N. Yavari, A.M. Tang, J.M. Pereira, G. Hassen, Canadian Geotechnical Journal 53, 1186 (2016)

[12] A.R. Mortezaie, M. Vucetic, Journal of Geotechnical and Geoenvironmental Engineering 139, 1727 (2013)

[13] ASTM, ASTM standard D3080-98, West Conshohocken, USA (1998)
[14] R.G. Campanella, J.K. Mitchell, Journal of Soil Mechanics and Foundations Division 94, 709 (1968)

[15] G. Baldi, T. Hueckel, R. Pellegrini, Canadian geotechnical journal 25, 807 (1988)

[16] L. Lemos, P. Vaughan, Géotechnique 50, 55 (2000)

[17] J.G. Potyondy, Geotechnique 11, 339 (1961) 